\title{
THE ROLE OF TREATMENT WITH HIGH-DOSE CORTICOSTEROIDS IN SEVERE LEPTOSPIROSIS WITH PULMONARY COMPLICATIONS
}

\author{
MARIA SATYA PARAMITHA ${ }^{1 *}$, SUTRISUNA ${ }^{1}$, MYRA PUSPITASARI $^{2}$
}

${ }^{1}$ Balaraja Hospital, Jalan Rumah Sakit No. 88, Tangerang, Banten, Indonesia, 15126, 2MRCC Siloam Hospital Semanggi, Jalan Garnisun Dalam No. 2-3, RT/RW 005/004, Karet, Semanggi, Jakarta, Indonesia, 12930

Email: maria.satya85@gmail.com

Received: 13 Dec 2018, Revised and Accepted: 10 Mar 2019

\section{ABSTRACT}

Objective: To investigate the effectiveness of high-dose corticosteroids in patients with severe leptospirosis, especially in reducing morbidity and mortality rates.

Methods: Literature searches were conducted using PubMed® and SCOPUS®. One systematic review and one systematic review with metaanalysis were selected from three chosen studies.

Results: The systematic review from Rodrigo et al. only included qualitative synthesis from four interventional studies. Early administration of methylprednisolone can be beneficial; however, low number and poor methodological quality of the studies question the validity of this review. Duggal et al. stated that there was no significant difference in the therapeutic effects of early high-dose corticosteroids (P $\geq 0.05$; $95 \%$ CI: 0.81-1.37), early low-dose corticosteroids ( $\mathrm{P} \geq 0.05$; 95\% CI: 0.3-1.03), and late low-dose corticosteroids (P $\geq 0.05$; 95\% CI: 0.11-2.52). Limited number of studies and high statistical heterogeneity, however, are major drawbacks for this review.

Conclusion: Evidence about the role of high-dose corticosteroids in severe leptospirosis patients with pulmonary complications, especially their benefits, is still limited. Additional randomized, controlled trials with adequate statistical power still need to be conducted.

Keywords: Severe leptospirosis, Acute Respiratory Distress Syndrome, High-dose corticosteroids

(C) 2019 The Authors. Published by Innovare Academic Sciences Pvt Ltd. This is an open access article under the CC BY license (http://creativecommons. org/licenses/by/4. 0/) DOI: http://dx.doi.org/10.22159/ijap.2019.v11s6.33546

\section{INTRODUCTION}

Leptospirosis is an acute infection caused by Leptospira spp. Its severity mainly depends on the virulence and toxins of the pathogens, as well as on the immune responses of the host. Acute Respiratory Distress Syndrome (ARDS) often occurs because of the loss of integrity of the epithelium or endothelium, and the release of cytokines. Consequently, the use of drugs that can decrease immunemediated reactions, such as corticosteroids, has been evaluated.

\section{Case Illustration}

A 19-year-old male patient was admitted to the inpatient ward with the chief complaint of fever for five days prior to hospital admission. Based on the history taken, the characteristics of his fever were sudden onset and continuously high body temperature without a clear trigger. Furthermore, the body temperature was not measured with appropriate devices. The patient also complained of abdominal pain and diarrhea for five days prior to hospital admission (three times a day, no mucus, no blood, yellowish brown color). The patient had been referred from the primary healthcare center because of a reduced platelet count $(39000 / \mu \mathrm{l})$. A history of previous hospitalization, similar clinical manifestation in the past, spontaneous bleeding, nausea and vomiting, decreased level of consciousness, seizures, cardiac disease, hematological problems, lung diseases, allergy, and previous trauma were denied. The patient was a farmer and often did not wear slippers when he worked. Recently, his neighborhood suffered from damage due to recurrent floods during the rainy season. The patient denied any consumption of medications.

Two days after his hospitalization, the patient complained of recurrent cough with blood (approximately $1 / 3-1 / 2$ volume of a cup) and of worsened weakness throughout his body. From physical examination, the patient appeared to be severely ill, and his level of consciousness was apathy. His blood pressure was $80 / 42 \mathrm{mmHg}$ (hypotension), his heart rate was 153 times per minute (tachycardia), his respiratory rate was 42 times per minute (tachypnea), and he had very low oxygen saturation (64\%). The patient also had anemic conjunctiva and ciliary suffusion in both eyes, crackles mixed with ronchi upon auscultation in both lungs, pain in the epigastric and right hypochondriac regions upon superficial abdominal palpation, and cold extremities.

The most recent laboratory results showed low hemoglobin (8.5 $\mathrm{g} / \mathrm{dl})$, low hematocrit $(24 \%)$, low erythrocyte counts $(2.92 \times$ $\left.10^{6} / \mathrm{mcL}\right)$, high white blood cell counts $(23010 / \mathrm{mcl})$, and low platelet counts $(46000 / \mathrm{mcl})$. The patient also had low blood sodium levels $(127 \mathrm{mmol} / \mathrm{l})$ and disturbed kidney functions (his blood urea level was $148 \mathrm{mg} / \mathrm{dl}$, and his blood creatinine level was $6.8 \mathrm{mg} / \mathrm{dl}$ ). His blood gas analysis indicated metabolic acidosis. Chest radiography showed infiltrates in both lungs.

The patient was diagnosed with septic shock and severe leptospirosis with Acute Respiratory Distress Syndrome (ARDS). The patient was then admitted to the Intensive Care Unit (ICU) and intubated. Methylprednisolone $2 \times 500 \mathrm{mg}$, a titration of norepinephrine and dobutamine, transamin $3 \times 500 \mathrm{mg}$, and vitamin $\mathrm{K}, 3 \times 1$ ampul, were administered.

\section{Background}

Leptospirosis is an acute infection, which can occur in humans and animals, and is caused by Leptospira spp. This disease was first discovered by Weil in 1886; thus, leading to the name Weil's disease for severe leptospirosis. Mice have been known as the main carrier of this pathogen. Although leptospirosis is more common in tropical countries, the worldwide burden of the disease has become one of the main health concerns, nowadays. According to the World Health Organization (WHO), the number of severe leptospirosis cases worldwide is more than approximately 500,000 cases per year (10 cases per 100,000 people living in tropical regions per year, and 0.110 cases per 100,000 people living in temperate regions). Clinical manifestations usually vary from unspecific acute fever to severe manifestations such as kidney failure, icterus, spontaneous bleeding, respiratory failure, and vascular collapse [1].

The pathogenesis of leptospirosis begins when the patient comes in contact with soil or water that has been contaminated with the 
pathogen. Through skin lesions, this pathogen will enter the bloodstream, actively breach the mucous membrane, and reach other organs (e. g., kidney, liver). Meanwhile, the immune system works against this pathogen by causing lysis of bacteria and release of antigens (glycolipoproteins, lipopolysaccharides, and endotoxins). These processes will lead to the activation of inflammatory cells (e. g., peripheral blood mononuclear cells) and to the induction of TNFalpha, IL-6, prostaglandin E2, and leukotriene B4 production, etc. Therefore, the severity of leptospirosis does not only depend on the virulence and toxins of the pathogens, but also on the intensity of the immune responses $[1,2]$.

The most severe manifestations of leptospirosis mainly occur in the lungs, kidneys, and the liver. ARDS or Acute Lung Injury (ALI) happen because of the loss of integrity of the epithelium or endothelium, and the release of cytokines (fig. 1). These factors cause edema and extravasation of proteins. In fatal cases, deposition of immunoglobulins in the alveolar septum may lead to pulmonary hemorrhage. As a result, until now, pulmonary hemorrhage has become the most common cause of death in patients with leptospirosis (rapid and severe manifestation with mortality rates up to $51 \%$ ). In $17-50 \%$ of patients with leptospirosis, the most common clinical manifestation is hemoptysis $[1,3]$. Glycolipoprotein that acts as a $\mathrm{Na}^{+} / \mathrm{K}^{+}$-ATPase inhibitor, is mainly involved in renal failure and electrolyte imbalance. In addition, inhibition of $\mathrm{Na}^{+} / \mathrm{K}^{+}$ATPase may also lead to functional disturbances of the liver, hypoalbuminemia, increased nonesterified fatty acids (NEFAs), and hyperbilirubinemia in plasma [1].

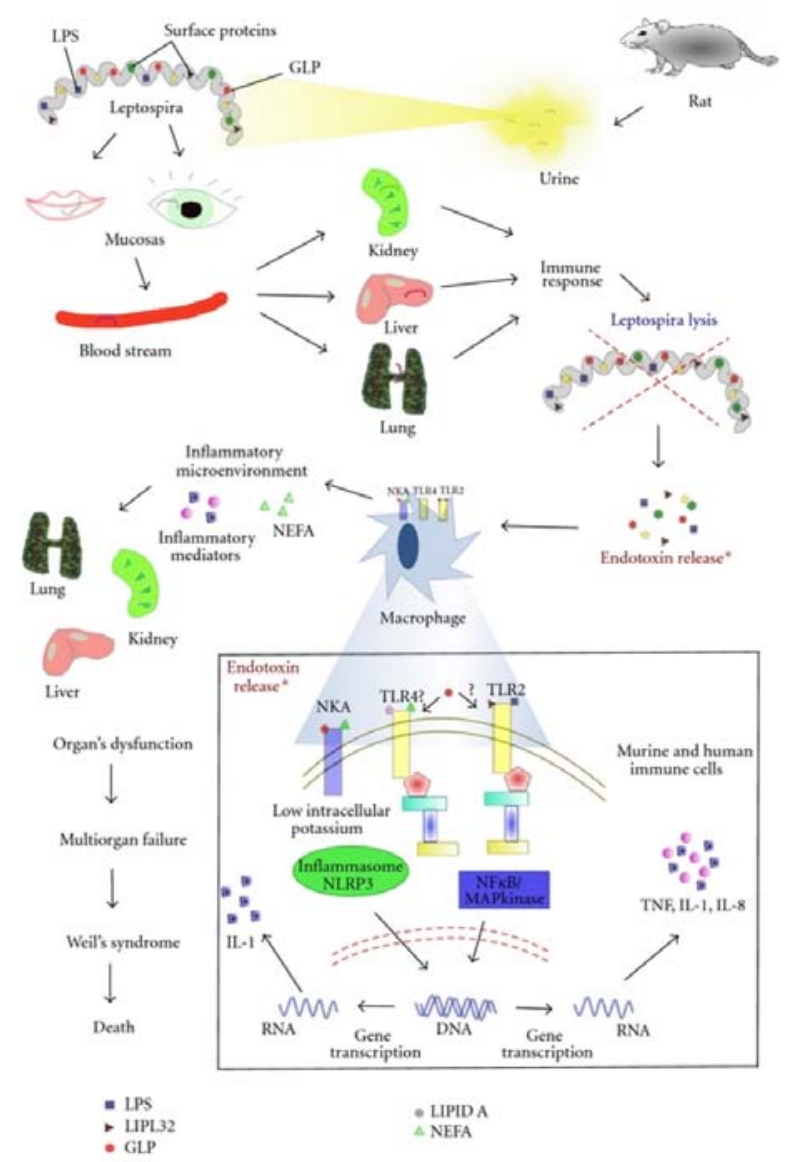

Fig. 1: Pathogenesis of severe leptospirosis [2]

As has been mentioned above, in severe leptospirosis, the immune response is highly correlated with multiple organ dysfunctions. A handful of studies have assessed the role of cell-mediated and humoral immunity in leptospirosis, and have detected immunochemical markers for the disease as well as several new mediators (e. g., human serum mannose-binding lectin) [4]. In a study by De Fost et al., markers of cell-mediated immunity, such as IFN-gamma-inducible-protein-10, granzyme B, and IFN-gammainduced monokine were increased in 44 patients with suspected severe leptospirosis [5]. As a result, the use of drugs that can decrease immune-mediated reactions, such as corticosteroids, has been evaluated in a considerable number of studies. This report will investigate further the effectiveness of high-dose corticosteroids in patients with severe leptospirosis, especially in reducing the morbidity and mortality rates of the patients.

\section{Clinical question}

Based on the case illustration, the clinical question is: "Is the administration of high-dose corticosteroids beneficial in decreasing mortality and morbidity rates from ARDS in patients with severe leptospirosis?"

We will answer this question using the PICO process, which is an acronym of the following:

- Population: Patients with severe leptospirosis

- Intervention/Indicator: Administration of high-dose corticosteroids

- Comparison: No administration of high-dose corticosteroids

- Outcome: Reduced mortality and morbidity rates from ARDS

\section{MATERIALS AND METHODS}

\section{Search strategy}

The articles were obtained from PubMed $₫$ and SCOPUS $₫$. The input of PICO-based keywords was performed using Boolean Operators (table 1). 
Table 1: Keywords used in the literature search

\begin{tabular}{|c|c|c|c|}
\hline Database & Keywords & Findings & Selected \\
\hline PubMed & $\begin{array}{l}\text { (("high-dose corticosteroid"[Title/Abstract]) OR ("corticosteroid"[Title/Abstract]) AND } \\
\text { ("leptospirosis"[Title/Abstract]) OR ("severe leptospirosis"[Title/Abstract]) OR ("Weil's } \\
\text { disease"[Title/Abstract])) }\end{array}$ & 5 & 2 \\
\hline Scopus & $\begin{array}{l}\text { TITLE-ABSTR-KEY(high-dose corticosteroid OR corticosteroid AND leptospirosis OR severe leptospirosis OR } \\
\text { Weil's disease) and TITLE-ABSTR-KEY(leptospirosis)[All Sources(Medicine and Dentistry)] }\end{array}$ & 2 & 1 \\
\hline
\end{tabular}

\section{Selection}

One systematic review and one systematic review with metaanalysis were selected from three retrieved studies based on the similarity to the PICO, study populations, language, as well as inclusion and exclusion criteria of the studies. The article was critically appraised afterwards, using standard criteria for interventional research (fig. 2).

Table 2: Critical appraisal of validity (Rodrigo et al. [2014]) [4]

Indicator
What clinical
question (PICO) did
the systematic review
address?

address?

Is it unlikely that studies were missed? used to select articles for inclusion

Were the included studies sufficiently validated for the type of question asked? important, relevant

Were the criteria appropriate?

\author{
Explanation \\ P: Adult patients with severe leptospirosis. \\ I: Treatment with high-dose corticosteroids. \\ C: Treatment without high-dose corticosteroids.
}

0 : Reduced mortality and morbidity due to pulmonary complications, including ARDS.

Clinical question: Does treatment with high-dose corticosteroids result in lower mortality and morbidity due to pulmonary complications in patients with severe leptospirosis?

Unclear.

- A comprehensive search strategy was applied to major bibliographic electronic databases (MEDLINE/PubMed, SciVerse Scopus). The search terms include all related keywords, including the alternative terms to expand the search strategy (e. g., "canicola fever", "mudwater fever", "canefield fever", and "swamp fever" were included as alternative terms of "leptospirosis"). The literature search was conducted and reported according to the PRISMA checklist.

- No date restrictions up to January 31 st 2014. Information about language restrictions is not included in the review.

- There were three reviewers who worked independently to evaluate all abstracts. All reviewers retrieved and read the full texts of these publications independently to confirm eligibility of the studies.

- Clinical trials about leptospirosis in which one or more trial arms included corticosteroids were also included in this systematic review.

- There were 260 records identified from the initial search (database searching and other sources, which are not specified by the authors). 152 records were screened after duplicates had been removed. After screening of title and abstract, only six full-text records were assessed for eligibility based on their relevance. Two out of six articles were excluded because the authors were unable to obtain the full text, and because one of them was an unpublished protocol for a randomized, controlled trial. Finally, four studies were included in the qualitative synthesis for this systematic review. - The authors also provided several case reports in this review, although they did not include the case reports in the main review because of the low quality of evidence and high possibility of publication bias.

No.

Inclusion criteria:

- The authors did not mention detailed information about the type of study, participants, intervention, and outcome measures. The authors included all interventional studies, including clinical trials.

Exclusion criteria:

- Studies that were not relevant to the review, according to the authors of the review.

- Studies where the full paper was not available.

Unclear.

Assessing of the methodological quality of the studies included:

- Three reviewers independently assessed the relevance to the review question. It is unclear, however, whether the formulation of the assessment questions was conducted and agreed to by all reviewers.

- The authors did not mention whether they performed any assessment of risk of bias and applicability or not.

- The authors did not comment on possible disagreements among the three review authors and on what kind of consensus was attempted (if any) to resolve them.

Methodologic quality of included studies:

- $\quad$ The authors considered all studies reviewed to have significant bias.

- Different treatment regimens of corticosteroids were used in different studies.

- There are only a small number of studies included in this systematic review, and these studies are of relatively poor methodological quality.

- Four out of five studies are prospective case series with either a single arm study or a comparison between a treatment group and a historical cohort.

- Three out of five studies had a small sample size with inadequate statistical power.

- There are no concerns relating to the applicability of all included studies, based on the reference standard used.

Unclear.

Were the results

similar from study to study?
The studies included did not undergo quantitative synthesis; therefore, there is no statistical representation of heterogeneity available from the studies.

\section{Critical appraisal}

Applying the literature search strategy explained in fig. 2, the author found two systematic reviews. The first was written by Rodrigo et al. (2014), and the second was written by Duggal et al. (2015). Critical appraisal of these systematic reviews concerning their validity, importance, and applicability was performed using the recommendations and tools of the Centre for Evidence-Based Medicine, University of Oxford. Critical appraisal of applicability was conducted using the Critical Appraisal Skills Program (CASP) (table 2-4). 


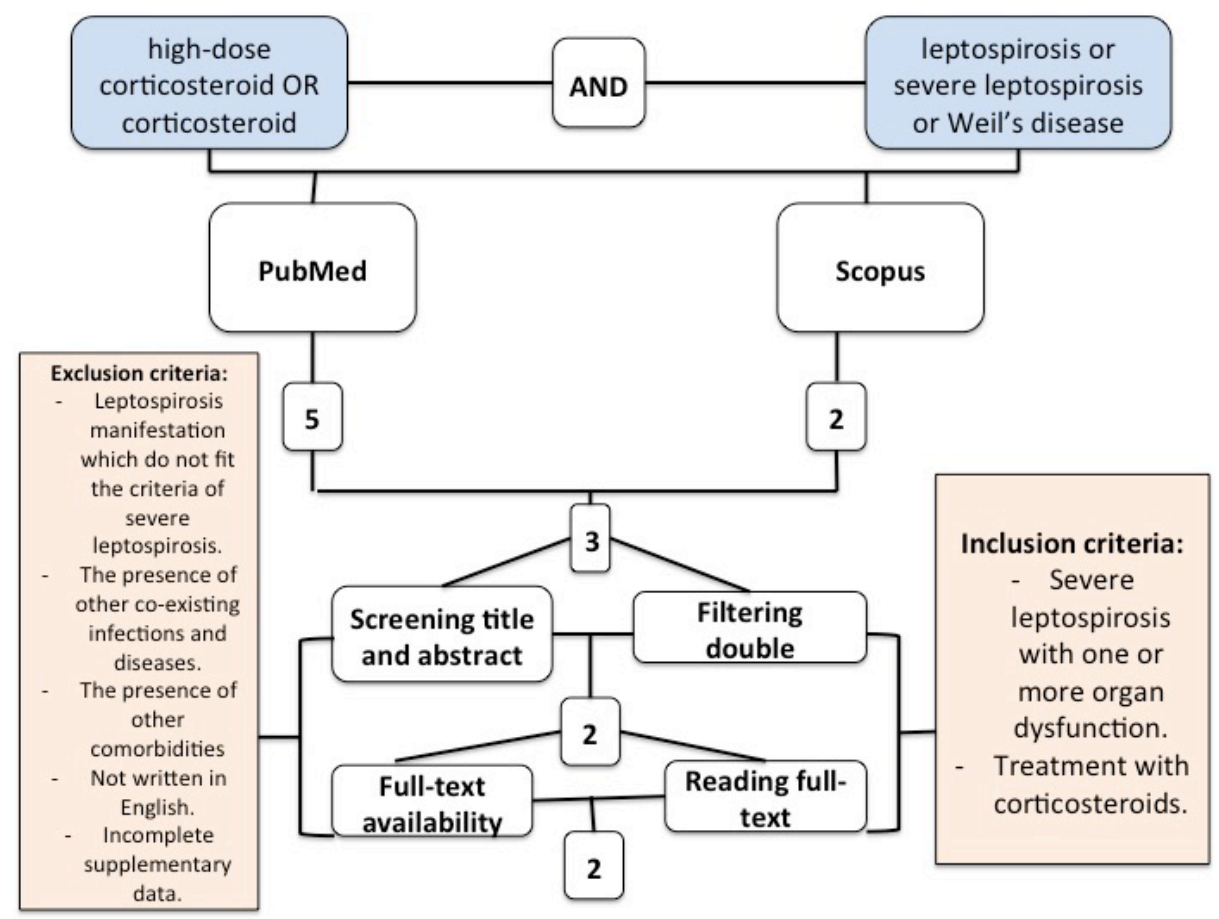

Fig. 2: Flow chart of literature searching (July 30th, 2018)

Table 3: Critical appraisal of importance (Rodrigo et al. [2014]) [4]

\begin{tabular}{|c|c|}
\hline Indicator & Explanation \\
\hline $\begin{array}{l}\text { How are the } \\
\text { results presented, } \\
\text { and what are the } \\
\text { main results? }\end{array}$ & $\begin{array}{l}\text { - The results are presented in table form. They consist of a qualitative synthesis of methodology, sample size, results, and } \\
\text { limitations. } \\
\text { - An additional table is provided to present brief descriptions of several case reports relevant to the systematic review. An } \\
\text { analysis of these case reports, however, is not included in the main review. Eight out of ten case reports supported the use of } \\
\text { intravenous steroids in patients with severe leptospirosis. Five out of the eight cases that showed successful steroid } \\
\text { treatment in patients with pulmonary complications. } \\
\text { - The authors generally recommended a short course of a moderate dose of steroids in severe leptospirosis patients with } \\
\text { pulmonary complications, specifically ARDS, within } 12 \mathrm{~h} \text { of diagnosis. The use of higher doses of steroid is still questionable } \\
\text { because one of the studies (Niwattayakul et al.) suggested a higher risk of nosocomial infections associated with high-dose } \\
\text { steroid treatment. The authors also suggested the possibility of using empirical antibiotics if there is a high risk of nosocomial } \\
\text { infections. The authors still addressed the limited availability of appropriate scientific evidence as the main hindrance toward } \\
\text { adequate recommendation of this treatment. }\end{array}$ \\
\hline $\begin{array}{l}\text { How precise are } \\
\text { the results? }\end{array}$ & $\begin{array}{l}\text { Precision is not addressed statistically by the authors in this review. However, the authors mentioned a low quality of the } \\
\text { evidence gathered from five studies included in the review, mainly because of their poor methodological quality, small } \\
\text { sample size, differences in timing and dosing of corticosteroids among the studies, lack of clear outcome measures (definition } \\
\text { of improved pulmonary conditions or pulmonary mortality, and overall mortality rates), and lack of clear and uniform, } \\
\text { clinical and immunological diagnostic criteria of ARDS. }\end{array}$ \\
\hline
\end{tabular}

Table 4: Critical appraisal of applicability (Rodrigo [2014]) [4]

\begin{tabular}{ll}
\hline Indicator & Explanation \\
\hline $\begin{array}{l}\text { Can the results be } \\
\text { applied to the local } \\
\text { population? }\end{array}$ & $\begin{array}{l}\text { leptospirosis incidence. Lack of awareness and low educational background may also contribute to the development of } \\
\text { severe leptospirosis or multi-organ dysfunctions in some patients, who only seek medical treatment after severe } \\
\text { manifestations have developed. }\end{array}$ \\
& - Almost all medical facilities in Indonesia use corticosteroids in various doses for inpatient and outpatient medical \\
& treatments. \\
& - Diagnosis of ARDS can be established through physical and radiological examinations in almost all medical facilities in \\
Indonesia. & \\
Are the benefits & The benefit of high-dose corticosteroid treatment is still questionable because of insufficient evidence and recommendations. \\
worth the harms & The increased risk of nosocomial infections with high-dose corticosteroid use still needs to be considered, especially if the \\
and costs? & medical facility is unable to provide adequate facilities and staff for strict monitoring afterwards. \\
Conclusion & Applicable in medical facilities with adequate standard operational procedures for intensive monitoring of the patients.
\end{tabular}

Based on the critical appraisal of validity and importance, the article by Rodrigo et al. cannot be considered valid and important; however, this article can be applied well to the Indonesian population because of the high number of similar cases. There is an increased demand for therapeutic improvement to reduce morbidity and mortality rates. 
Based on the critical appraisal of validity and importance, the article by Duggal et al. is considered valid and important. The content of this systematic review is also considered applicable to the population of Indonesia (table 5-7).

Table 5: Critical appraisal of validity (Duggal et al. [2015]) [5]

\begin{tabular}{l}
\hline Indicator \\
\hline What clinical question \\
(PICO) did the \\
systematic review \\
address?
\end{tabular}

address?

Is it unlikely that important, relevant studies were missed?

Were the criteria used to select articles for inclusion appropriate?

Were the included studies sufficiently valid for the type of question asked?

Were the results similar from study to study?

\section{Explanation}

P: Adult patients with ARDS.

I: Various types of pharmacologic therapy (cisatracurium, granulocyte macrophage colony-stimulating factor, early highdose corticosteroids, late low-dose methylprednisolone, early low-dose methylprednisolone, prostaglandin E1, salbutamol, surfactant, pentoxifylline, ketoconazole, lisofylline, interleukin-10, Xuebijing, simvastatin, activated protein C, ALT-836, dazoxiben, indomethacin, acyclovir, inactivated factor VIIa).

C: Placebo or no therapy.

$0:$ Reduced all-cause mortality at or before three months after randomization.

Clinical question: What are the effects of various pharmacologic therapies compared with placebo or no therapy on allcause mortality at or before three months after randomization in adult patients with ARDS? Yes

- A comprehensive search strategy involving several electronic databases (OVID versions of CENTRAL, CINAHL, MEDLINE, EMBASE) was used. A highly sensitive strategy was used by the authors to search for randomized, controlled trials from MEDLINE with several modifications to retrieve articles from EMBASE, CINAHL, and OVID versions of CENTRAL. The literature search for articles published before 2009 was conducted in the HEALTHSTAR database. A literature search was also performed on abstracts from conference proceedings (1994-2012) that had been published in the American Journal of Respiratory and Critical Care Medicine, Chest, Critical Care Medicine, and Intensive Care Medicine.

- No language restrictions were applied.

- There were two reviewers who worked independently to review all studies. The same reviewers also confirmed the eligibility of the studies by reading the full-text version of the articles.

- There were two authors who independently extracted the data on participants, intervention, and outcome from all studies. A standardized form was filled out by the authors during the data extraction process.

- Unclear data of the primary outcome were clarified by the authors of the original studies.

- A systematic evaluation of the mechanistic quality of the pharmacologic therapies included in the studies was not performed; however, a methodological quality assessment was still conducted and agreed to by the reviewers.

- After the initial phase of searching, 13461 articles (including conference abstracts and bibliographies) were obtained for screening. After screening for relevance to the topic of this systematic review, 118 studies were obtained. After the exclusion process, 58 studies (consisting of 58 trials, 21 classes of drugs, and 6635 patients with available data for primary outcomes) were chosen and assessed for eligibility.

Yes.

Inclusion criteria:

- Type of the study: randomized controlled trials.

- Type of the participants: adult patients with any grade of severity of ARDS admitted to an ICU. Definition of mild ARDS or ALI can be used from previous nomenclature or based on American-European Consensus Conference (AECC) criteria or defined by the authors.

- Type of intervention: comparison between pharmacological therapy and placebo, or no therapy.

- Type of outcome measurement: all-cause mortality at or prior to three months after samples were randomized.

Outcome measures consist of 90-days mortality, 60-days mortality, hospital mortality, and ICU mortality.

Exclusion criteria:

- Trials that require subgroup analysis.

- Trials that evaluated enteral and parenteral nutritional interventions, fluid interventions, inhalation therapy with nitric oxide, mechanical ventilation, or medical oxygen.

- Trials that compare two pharmacological agents into treatment group and placebo group. Yes.

Assessing the methodological quality of the studies included:

- Methodological quality assessment was performed based on random sequence generation, allocation concealment, blinding of caregivers and outcome assessors, attrition bias, and analysis of primary outcomes (whether they are aligned with intention-to-treat principle and completeness of follow-up after intervention).

- If there is any disagreement among the authors or reviewers during the process, the final decision is determined by consensus and with consultation of senior authors.

- An acceptable reference standard was used in all studies.

No. Statistical heterogeneity of average sensitivities, specificities, and likelihood ratios of positive and negative test results using the $\mathrm{I}^{2}$ and chi-squared statistics were present. The results showed $\mathrm{I}^{2}$ values greater than $50 \%$ or P-values less than 0.1, which indicated high heterogeneity. Subgroup analysis based on MRI sequences was performed to explore heterogeneity further.

Table 6: Critical appraisal of importance (Duggal et al. [2015]) [5]

\begin{tabular}{|c|c|}
\hline Indicator & Explanation \\
\hline $\begin{array}{l}\text { How are the results } \\
\text { presented, and what } \\
\text { are the main results? }\end{array}$ & $\begin{array}{l}\text { - Mortality data for each pharmacological agent were pooled, if the reviewers judged and identified clinically similar } \\
\text { results from more than one study. If, in the study, samples were randomized to more than one dose, all doses would be } \\
\text { grouped into one treatment arm. The results of the methodological quality appraisal were: clear description of random } \\
\text { allocation in } 24(42.1 \%) \text { trials; clear concealed allocation in } 24(42.1 \%) \text { trials; low risk of performance bias due to blinding } \\
\text { of caregivers in } 44 \text { trials }(77.2 \%) \text {, and due to complete follow-up in } 42(73.7 \%) \text { trials. Low risk of bias in all domains was } \\
\text { found in } 12(21.1 \%) \text { trials. } \\
\text { - Comparisons between treatment arm and control arm were analyzed using relative risk (RR) and } 95 \% \text { confidence } \\
\text { interval (CI). A statistically significant result was obtained when the P-value was less than } 0.05 \text {. }\end{array}$ \\
\hline
\end{tabular}




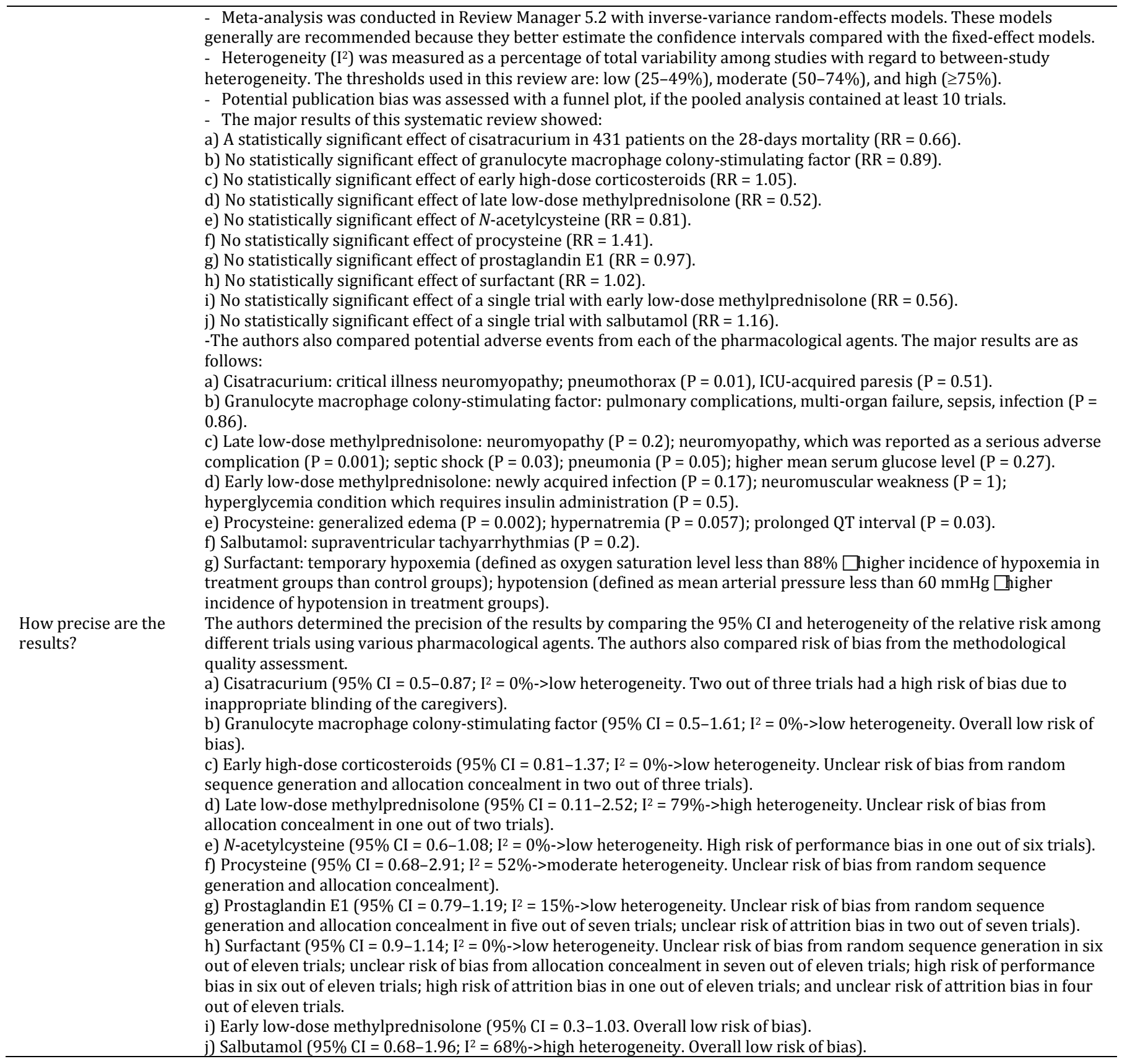

Table 7: Critical appraisal of applicability (Duggal et al. [2015]) [5]

\begin{tabular}{|c|c|}
\hline Indicator & Explanation \\
\hline $\begin{array}{l}\text { Can the results be } \\
\text { applied to the } \\
\text { local population? }\end{array}$ & $\begin{array}{l}\text { - As a developing country with tropical conditions and relatively high humidity, Indonesia also faces a problem of high } \\
\text { leptospirosis incidence. A lack of awareness and low educational background may also contribute to the development of } \\
\text { severe leptospirosis or multi-organ dysfunctions in some patients, who only seek medical treatment after severe } \\
\text { manifestations have developed. } \\
\text { - Almost all medical facilities in Indonesia use corticosteroids in various doses for inpatient and outpatient medical } \\
\text { treatments. } \\
\text { - Diagnosis of ARDS can be established through physical and radiological examinations in almost all medical facilities in } \\
\text { Indonesia. }\end{array}$ \\
\hline $\begin{array}{l}\text { Are the benefits } \\
\text { worth the harms } \\
\text { and costs? } \\
\text { Conclusion }\end{array}$ & $\begin{array}{l}\text { The benefit of high-dose corticosteroid is still questionable because of insufficient evidence and recommendations. The } \\
\text { increased risk of nosocomial infections and other serious adverse events upon corticosteroid use also still needs to be } \\
\text { considered, especially if the medical facility is unable to provide adequate facilities and staff for strict monitoring afterwards. } \\
\text { Applicable in medical facilities with adequate standard operational procedures for intensive monitoring of patients. }\end{array}$ \\
\hline
\end{tabular}

\section{RESULTS}

The systematic review by Rodrigo et al. consists of four interventional studies with brief descriptions of 10 case reports with a similar topic. The aim of this systematic review is to evaluate benefits of high-dose corticosteroid treatment in patients with severe leptospirosis. The earliest study mentioned in this review is a single-arm, prospective, interventional pilot study by Ittyachen et al. 
published in 2015. This study only included eight ICU patients with ARDS and leptospirosis, and provided no information about specific laboratory diagnostic criteria. All patients were treated with intravenous methylprednisolone (initial dose: $4 \times 40 \mathrm{mg}$; mostly for four days), standard treatment, and noninvasive ventilation. The investigators concluded that methylprednisolone is a life-saving adjuvant when combined with standard treatment and noninvasive ventilation in patients with ARDS and leptospirosis because $87 \%$ of the patients survived and managed to recover completely after two weeks of treatment [4].

Another prospective study from this systematic review is a study by Kularatne et al. published in 2011. This study describes the results of 78 severe leptospirosis patients treated with bolus intravenous methylprednisolone $(500 \mathrm{mg}$ daily for the first three days, continued with oral methylprednisolone, $8 \mathrm{mg}$ daily for five days) and compared with retrospective cohort with one year duration of treatment. The investigators diagnosed leptospirosis with the Microscopic Agglutination Test (MAT). The investigators also classified the severity of organ impairment with a scoring system that ranged from zero to six. If the score was at least two, administration of methylprednisolone was required. Ten patients were excluded from the study because they were terminally ill. In patients with a score of four who were treated with methylprednisolone, the survival rate was $100 \%$. This rate was significantly higher $(\mathrm{P}<0.001)$ than with the patients with a similar score who were not treated with methylprednisolone (38\%). However, no significant difference in the survival rate was observed in patients with a score of five or six (severe organ impairment) treated with methylprednisolone [4].

In the study by Shenoy et al., the investigators also used bolus intravenous methylprednisolone in 30 leptospirosis patients with pulmonary complications. The diagnosis of leptospirosis was confirmed with IgM ELISA (Enzyme-Linked Immunosorbent Assay) in this article, while the diagnosis of ARDS was confirmed by clinical manifestation or diffuse pulmonary infiltrates from radiological examination. A comparison was made between the group that received intravenous methylprednisolone (bolus, $1 \mathrm{~g}$ daily for the first three days, continued with oral prednisolone, $1 \mathrm{mg} / \mathrm{kg}$ daily for seven days) and the group that received only standard treatment. The investigators compared the survival rates and severity of pulmonary involvement using ALI and Acute Physiology and Chronic Health Evaluation III (APACHE) scores. The results showed significantly higher mortality rates $(\mathrm{P}<0.05)$ in the group treated with standard treatment $(62 \%)$ than with the group that received corticosteroids (18\%), except for patients who had four organ systems complications (pulmonary, hepatic, renal, hematological). In addition, the requirement of ventilator support was lower in the group that received corticosteroids. The investigators also found that there was a significantly better $(\mathrm{P}<0.005)$ response to corticosteroids in the presence of moderate-to-severe lung injury
(ALI score $>2.5$ and APACHE III score $>60$ ). Because all deceased patients in the group treated with corticosteroids died more than 12 $\mathrm{h}$ after they had suffered from difficulty of breathing, the investigators suggested that more benefits could be achieved in early administration of corticosteroids [4].

The last study in the systematic review by Rodrigo et al. is a prospective, randomized, controlled trial of desmopressin and highdose dexamethasone as an adjunctive treatment compared with standard treatment in severe leptospirosis patients with pulmonary complications. Sixty-eight patients were divided equally into three treatment groups: one group was treated with desmopressin $[0.3$ $\mathrm{mcg} / \mathrm{kgBW}$ in $50 \mathrm{ml}$ saline over $30 \mathrm{~min}$ daily per infusion), one group with dexamethasone $(200 \mathrm{mg}$ daily for the first three days, continued with $1 \mathrm{mg} / \mathrm{kg} /$ day oral prednisolone for four days). A confirmation of the diagnosis was made with Polymerase Chain Reactions (PCR) and MAT. Only 76\% of enrolled patients were finally confirmed as suffering from leptospirosis. The investigators concluded that there was no significant difference in mortality rates between the groups according to the intention-to-treat per protocol analysis. No significant differences in other outcome measures including duration of mechanical ventilation and bleeding were observed [4].

The second systematic review discussed in this manuscript was published by Duggal et al. in 2015. This review consists of 58 randomized, controlled trials with 21 classes of pharmacological agents, involving 6635 patients. This review aims to study the effect of various pharmacological agents in adult patients with ARDS compared with placebo or no therapy. The outcome measure is allcause mortality at or before three months after the patients are randomized (classified into 90-days mortality, 60-days mortality, hospital mortality, and ICU mortality). ARDS and ALI were diagnosed using the criteria defined by the AECC.

Overall, a wide range of pharmacological agents were examined in this review, including: prostaglandin- $\mathrm{E}_{1}$ (seven trials), $N$-acetylcysteine (six trials), early high-dose corticosteroids (three trials), late low-dose corticosteroids (two trials), early low-dose corticosteroids (one trial), surfactant (eleven trials), neutrophil elastase inhibitors (six trials), cisatracurium (three trials), intravenous salbutamol (two trials), granulocyte macrophage-colony stimulating factor (two trials), procysteine (two trials), dazoxiben (one trial), acyclovir (one trial), indomethacin (one trial), pentoxifylline (one trial), interleukin-10 (one trial), ketoconazole (one trial), lisofylline (one trial), activated protein C (one trial), inactivated factor VIIa (one trial), simvastatin (one trial), Xuebijing (one trial), inhaled albuterol (one trial), and anti-tissue factor antibody or ALT-386 (one trial) [5]. The statistical analysis of the comparison between treatment and control arms is based on relative risk, 95\% confidence interval, and determination of P-value. In addition, meta-analysis and measurement of heterogeneity were conducted (table 8).

Table 8: Statistical analysis of the comparison of the effects of each pharmacological agent and placebo, or no therapy in adult patients with ARDS from all randomized, controlled trials included in this review [5]

\begin{tabular}{|c|c|c|c|c|}
\hline Pharmacological agents & Relative risk (RR) & P-value & 95\% Confidence interval (CI) & $I^{2}$ (Heterogeneity) \\
\hline Cisatracurium & 0.66 & $<0.05$ & $0.5-0.87$ & $0 \%$ \\
\hline Granulocyte macrophage colony-stimulating factor & 0.89 & $\geq 0.05$ & $0.5-1.61$ & $0 \%$ \\
\hline Early high-dose corticosteroids & 1.05 & $\geq 0.05$ & $0.81-1.37$ & $0 \%$ \\
\hline Late low-dose corticosteroids & 0.52 & $\geq 0.05$ & $0.11-2.52$ & $79 \%$ \\
\hline Early low-dose corticosteroids & 0.56 & $\geq 0.05$ & $0.3-1.03$ & - \\
\hline $\mathrm{N}$-acetylcysteine & 0.81 & $\geq 0.05$ & $0.6-1.08$ & $0 \%$ \\
\hline Procysteine & 1.41 & $\geq 0.05$ & $0.68-2.91$ & $52 \%$ \\
\hline Prostaglandin E1 & 0.97 & $\geq 0.05$ & $0.79-1.19$ & $15 \%$ \\
\hline Surfactant & 1.02 & $\geq 0.05$ & $0.9-1.14$ & $0 \%$ \\
\hline Salbutamol & 1.16 & $\geq 0.05$ & $0.68-1.96$ & $68 \%$ \\
\hline
\end{tabular}

The investigators also described the potential risk of bias for each study. Potential bias is mainly classified as bias from random sequence generation, bias from allocation concealment, performance bias, and attrition bias. The authors also described potential adverse effects that had been found in all studies and included how statistically significant the possibility of having each of the adverse effects is (table 9) [5]. 
Table 9: Potential adverse effects of various pharmacological agents for treating ARDS in adult patients [5]

\begin{tabular}{|c|c|c|}
\hline Pharmacological agents & Potential adverse effects & Clinical/Statistical significance \\
\hline \multirow[t]{3}{*}{ Cisatracurium } & Critical illness neuromyopathy & 1/18 patients per group \\
\hline & Pneumothorax & $\mathrm{P}$-value $=0.01$ \\
\hline & ICU-acquired paresis & $\mathrm{P}$-value $=0.51$ \\
\hline $\begin{array}{l}\text { Granulocyte macrophage colony- } \\
\text { stimulating factor }\end{array}$ & $\begin{array}{l}\text { Pulmonary complications, multi-organ failure, } \\
\text { sepsis, infection }\end{array}$ & $\mathrm{P}$-value $=0.86$ \\
\hline \multirow[t]{5}{*}{ Late low-dose corticosteroids } & Neuromyopathy & $P$-value $=0.2$ \\
\hline & Severe neuromyopathy & $\mathrm{P}$-value $=0.001$ \\
\hline & Septic shock & $\mathrm{P}$-value $=0.03$ \\
\hline & Pneumonia & $\mathrm{P}$-value $=0.05$ \\
\hline & Higher mean serum glucose level & $\mathrm{P}$-value $=0.27$ \\
\hline \multirow[t]{3}{*}{ Early low-dose corticosteroids } & Newly-acquired infections & $\mathrm{P}$-value $=0.17$ \\
\hline & Neuromuscular weakness & $\mathrm{P}$-value $=1.0$ \\
\hline & Hyperglycemia & $\mathrm{P}$-value $=0.5$ \\
\hline \multirow[t]{3}{*}{ Procysteine } & Generalized edema & $\mathrm{P}$-value $=0.002$ \\
\hline & Hypernatremia & $\mathrm{P}$-value $=0.057$ \\
\hline & Prolonged QT interval & $\mathrm{P}$-value $=0.03$ \\
\hline Salbutamol & Supraventricular tachyarrhythmia & $\mathrm{P}$-value $=0.2$ \\
\hline \multirow[t]{2}{*}{ Surfactant } & Temporary hypoxemia (oxygen saturation<88\%) & $\begin{array}{l}51.9 \% \text { in treatment group and } 25.2 \% \text { in control } \\
\text { group }\end{array}$ \\
\hline & Hypotension (mean arterial pressure $<60 \mathrm{mmHg}$ ) & $\begin{array}{l}34.1 \% \text { in treatment group and } 17.1 \% \text { in control } \\
\text { group }\end{array}$ \\
\hline
\end{tabular}

As a whole, the results of both systematic reviews are applicable to the Indonesian population because of its increasing number of severe leptospirosis cases (table 10). In addition, many medical facilities in Indonesia, especially in big cities, have used corticosteroids in various doses for both inpatient and outpatient therapeutic regimens. Additional examinations to confirm the diagnosis of ARDS (for example: radiological examination and arterial blood gases analysis) are also widely used. Therefore, in the presence of adequate facilities, health professionals, and good standard operational procedures to monitor patients closely, the use of high-dose corticosteroids will be beneficial.

Table 10: Determination of level of evidence for each of the studies based on validity criteria

\begin{tabular}{lllllll}
\hline Article & Year & \multicolumn{2}{l}{ Validity } & & Level of \\
& & & PICO & $\begin{array}{l}\text { Appropriate } \\
\text { searching }\end{array}$ & $\begin{array}{l}\text { Inclusion of relevant } \\
\text { studies }\end{array}$ & $\begin{array}{l}\text { Quality } \\
\text { assessment }\end{array}$ \\
\hline Rodrigo, et al. & 2014 & $(+)$ & $(-)$ & $(-)$ & $(-)$ & $(+)$ \\
Duggal, et al. & 2015 & $(+)$ & $(+)$ & $(+)$ & $(+)$ & $(-)$ \\
\hline
\end{tabular}

Legends: $(+)=$ mentioned clearly in the article; $(-)=$ in not mentioned or unclear explanation in the article levels of evidence are determined based on the criteria from the Oxford centre of evidence-bases medicine

Table 11: Scoring of acute lung injury (ALI) [6]

\begin{tabular}{|c|c|}
\hline Components & Values \\
\hline \multicolumn{2}{|l|}{ Chest X-Ray score } \\
\hline No alveolar consolidation & 0 \\
\hline Alveolar consolidation confined to 1 quadrant & 1 \\
\hline Alveolar consolidation confined to 2 quadrants & 2 \\
\hline Alveolar consolidation confined to 3 quadrants & 3 \\
\hline Alveolar consolidation in all 4 quadrants & 4 \\
\hline \multicolumn{2}{|c|}{ Hypoxemia score (arterial oxygen tension to inspired oxygen concentration ratio) } \\
\hline $\mathrm{PaO}_{2} / \mathrm{FiO}_{2} \geq 300$ & 0 \\
\hline $\mathrm{PaO}_{2} / \mathrm{FiO}_{2} 225-299$ & 1 \\
\hline $\mathrm{PaO}_{2} / \mathrm{FiO}_{2} 175-224$ & 2 \\
\hline $\mathrm{PaO}_{2} / \mathrm{FiO}_{2} 100-174$ & 3 \\
\hline $\mathrm{PaO}_{2} / \mathrm{FiO}_{2}<100$ & 4 \\
\hline \multicolumn{2}{|c|}{ Positive end expiratory pressure score (PEEP) if the patient is ventilated } \\
\hline $\mathrm{PEEP} \geq 5 \mathrm{cmH}_{2} \mathrm{O}$ & 0 \\
\hline PEEP $6-8 \mathrm{cmH}_{2} \mathrm{O}$ & 1 \\
\hline PEEP $9-11 \mathrm{cmH}_{2} \mathrm{O}$ & 2 \\
\hline PEEP $12-14 \mathrm{cmH}_{2} \mathrm{O}$ & 3 \\
\hline $\mathrm{PEEP} \geq 15 \mathrm{cmH}_{2} \mathrm{O}$ & 4 \\
\hline \multicolumn{2}{|c|}{ Respiratory system compliance score (if available) } \\
\hline Compliance $\geq 80 \mathrm{ml} / \mathrm{cmH}_{2} \mathrm{O}$ & 0 \\
\hline Compliance $60-79 \mathrm{ml} / \mathrm{cmH}_{2} \mathrm{O}$ & 1 \\
\hline Compliance $40-59 \mathrm{ml} / \mathrm{cmH}_{2} \mathrm{O}$ & 2 \\
\hline Compliance $20-39 \mathrm{ml} / \mathrm{cmH}_{2} \mathrm{O}$ & 3 \\
\hline Compliance $\leq 19 \mathrm{ml} / \mathrm{cmH}_{2} \mathrm{O}$ & 4 \\
\hline \multicolumn{2}{|c|}{ Final scores (dividing the aggregate sum by the number of components used) } \\
\hline No lung injury & $\mathbf{0}$ \\
\hline Mild-to-moderate lung injury & $0.1-2.5$ \\
\hline Severe lung injury (ARDS) & $>2.5$ \\
\hline
\end{tabular}




\section{DISCUSSION}

The author evaluated two systematic reviews, with one of the reviews contains a meta-analysis. The first systematic review, from Rodrigo et al., only included a qualitative synthesis from four studies. The clinical question addressed by that article is similar to the clinical question in this manuscript. Unfortunately, because the authors did not explain the search process in the method section in more detail, it is still unclear whether important and relevant studies were missed, which puts the validity of this article into question. The authors also did not specify any inclusion criteria for the type of study, participants, intervention, and outcome measures. In addition, the small number of studies and their poor methodological quality (e. g., small sample size, which lowers the adequacy of statistical power and increases the risk of bias) also contributed to the questionable validity of the conclusions from this systematic review [4].

Uniformity of treatment regimens of corticosteroids and definition of pulmonary involvement also becomes a problem for both systematic reviews. In the systematic review by Rodrigo et al., for example, the dose of dexamethasone, which had been used in the study by Niwattayakul $e t$ $a l$., was high in comparison with the dose of methylprednisolone in the study by Shenay et al. Differences in doses in both studies might contribute to statistically significant higher numbers of nosocomial infections in the study by Niwattayakul et al. Other confounding factors, which might result from these differences, were frequency of treatment, duration of treatment, oral drugs and/or antibiotics [4]. To define the severity of pulmonary complications, Rodrigo et al. used ALI (table 11) [6] and APACHE III [4, 6] scores, while Duggal et al. used criteria from the AECC (table 12) [5, 7].

Table 12: Recommended criteria by the AACE on Acute Lung Injury (ALI) and acute respiratory distress syndrome (ARDS) [7]

\begin{tabular}{lllll}
\hline Criteria & Timing & Oxygenation & Chest radiograph & Pulmonary artery wedge pressure \\
\hline ALI & Acute & $\mathrm{PaO}_{2} / \mathrm{FiO}_{2} \leq 300$ & Bilateral infiltrates seen on frontal & $\leq 18 \mathrm{mmHg}$ when measured or no clinical evidence of \\
& onset. & $\mathrm{mmHg}^{2}$ & chest radiograph. & left atrial hypertension. \\
ARDS & $\begin{array}{l}\text { Acute } \\
\text { onset. }\end{array}$ & $\begin{array}{l}\mathrm{PaO}_{2} / \mathrm{FiO}_{2} \leq 200 \\
\mathrm{mmHg} .\end{array}$ & $\begin{array}{l}\text { Bilateral infiltrates seen on frontal } \\
\text { chest radiograph. }\end{array}$ & $\leq 18 \mathrm{mmHg}$ when measured or no clinical evidence of \\
& & & left atrial hypertension.
\end{tabular}

Although the evidence and recommendations provided by Rodrigo et al. were limited, the authors suggested that early administration (within $12 \mathrm{~h}$ of diagnosis) of methylprednisolone may be beneficial in severe leptospirosis patients with pulmonary complications. This conclusion, however, contradicts the conclusion from the systematic review by Duggal et al., which stated that there was no significant difference in therapeutic effects of early high-dose corticosteroids, early low-dose corticosteroids, and late low-dose corticosteroids. It needs to be kept in mind, however, that even though Duggal et al. were one step ahead of Rodrigo et al. by providing a quantitative and qualitative synthesis of randomized controlled trials, the systematic review itself still needs further improvement due to the limited number of studies (only one study for early low-dose methylprednisolone) and high statistical heterogeneity from two studies with late low-dose methylprednisolone $[4,5]$.

To conclude, evidence about the role of high-dose corticosteroids in severe leptospirosis patients with pulmonary complications, especially about their benefits, is still limited. Additional randomized, controlled trials with adequate statistical power still need to be conducted. Several methodological qualities need more careful attention, such as: clinical and immunological diagnostic criteria; exclusion of infectious processes with similar clinical manifestation; clear definition of disease severity and uniformity of scoring systems; uniformity of doses and duration of corticosteroid treatment; clarity and uniformity in outcome measurements. Studies with an adequate sample size and study type must also be considered.

\section{ACKNOWLEDGMENT}

This article was presented at The $3^{\text {rd }}$ International Conference and Exhibition on Indonesian Medical Education and Research Institute (ICE on IMERI 2018), Faculty of Medicine, Universitas Indonesia, Jakarta Indonesia. The authors want to express their gratitude to RSUD Balaraja for the support given to conduct a case study. The authors also want to express their biggest gratitude to Dr. Myra Puspitasari, SpPD, MKes for supervising this study from the beginning until its publication. We thank the $3^{\text {rd }}$ ICE on IMERI Committee who had supported the peer review and manuscript preparation before submitting to the journal.

\section{AUTHORS CONTRIBUTIONS}

All the author have contributed equally

\section{CONFLICT OF INTERESTS}

Declared none

\section{REFERENCES}

1. Zein U. Leptospirosis. In: Setiati S, Alwi I, Sudoyo AW, Simadibrata M, Setiyohadi B, Syam AF. editors. Buku ajar ilmu penyakit dalam. $6^{\text {th }}$ ed. Jakarta: Interna Publishing; 2015. p. 633-8.

2. Gonçalves-de-Albuquerque $\mathrm{CF}$, Burth $\mathrm{P}$, Silva $\mathrm{AR}$, Younes Ibrahim M, Castro-Faria Neto HC, Castro Faria MV. Review article: Leptospira and inflammation. Mediators Inflamm 2012;1-11. http://dx.doi.org/10.1155/2012/317950

3. Gulati S, Gulati A. Pulmonary manifestation of leptospirosis. Lung India 2012;29:347-53.

4. Rodrigo C, de Silva NL, Goonaratne R, Samarasekara K, Wijesinghe I, Parththipan B, et al. High-dose corticosteroids in severe leptospirosis: a systematic review. Trans R Soc Trop Med Hyg 2014;108:743-50.

5. Duggal A, Ganapathy A, Ratnapalan M, Adhikari NKJ. Pharmacological treatments for acute respiratory distress syndrome: Systematic review. Minerva Anestesiol 2015;81:567-88.

6. Murray JF, Matthay MA, Luce JM, Flick MR. An expanded definition of the adult respiratory distress syndrome. Pulmonary perspectives. Am Rev Respir Dis 1988;138:720-3.

7. Bernard GR, Artigas A, Brigham KL, Carlet J, Falke K, Hudson L, et al. The American European consensus conference on ARDS: definitions, mechanisms, relevant outcomes, and clinical trial coordination. Am J Respir Crit Care Med 1994;149:818-24. 